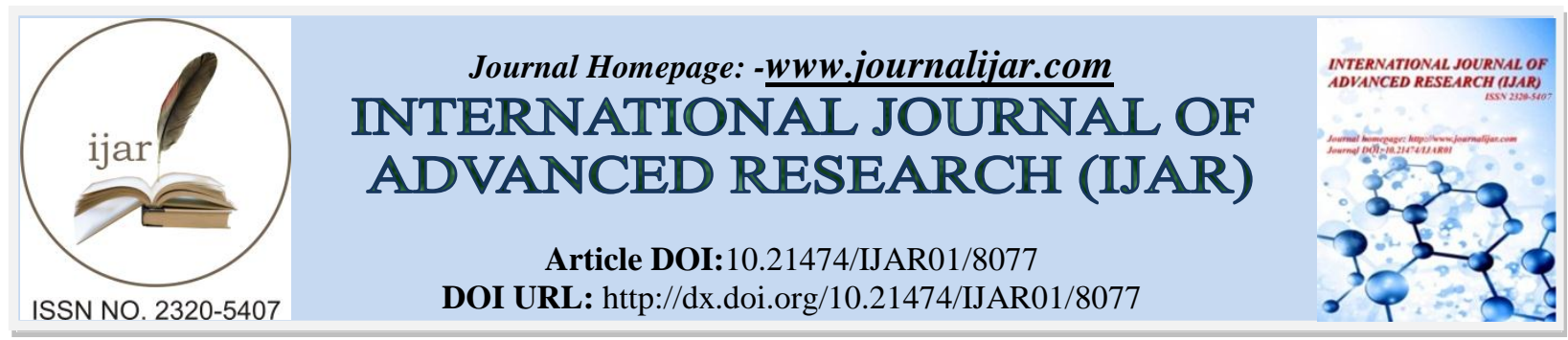

RESEARCH ARTICLE

\title{
ORAL CYSTICERCOSIS: A RARE DIFFERENTIAL DIAGNOSIS FOR ORAL SWELLINGS.
}

\section{Priyanka Mittal ${ }^{1}$, Bhuvan Nagpal ${ }^{2}$, Aditya Garg $^{3}$, Raman Mittal ${ }^{4}$, Anupam Nagpal $^{5}$, AnuradhaGarg ${ }^{6}$ and Jyotsana Nagpal ${ }^{7}$.}

1. MBBS, MD (Pathology); Consultant Pathologist, Hisar, India.

2. MDS (Oral Pathology), MBA (Hosp. Mgt.), PG Dip. (Medico-Legal Systems); Consultant Oral Pathologist, Chief Administrative Officer \& Medico-Legal Expert, Jind Manglam Diagnostics, Jind, India.

3. MBBS; Post Graduate Resident, Dept. of Anaesthesia, TeerthankerMahaveer Medical College \& Research Centre, Moradabad, India.

4. MBBS, DMRD (Radiology); Consultant Radiologist, Manglam Diagnostics, Hansi, Hisar, India.

5. BDS, MBA (Hosp. Mgt.); Consultant \& HOD, Dept. of Dental Surgery, Lifeline Institute of Medical Sciences, Hisar, India.

6. MBBS; Medical Officer (HCMS-I), CHC, Uklana, Hisar, India.

7. Ph.D. (Biotechnology) (CSIR-CSIO, Chandigarh); Consultant in Molecular Biology, Tohana Manglam Diagnostics, Tohana, India.

\section{Manuscript Info}

Manuscript History

Received: 11 September 2018

Final Accepted: 13 October 2018

Published: November 2018

Keywords:

cysticercosis, oral, tongue, taenia, helminth, pork, tapeworm.

\section{Abstract}

Cysticercosis is a major public health problem worldwide particularly in developing countries. It is a potentially fatal helminthic disease commonly seen in India, Southern Africa, Latin America and Eastern Europe which results from infection with the larval stage of the tapeworm, Taeniasolium. It is a condition in which human beings act as the intermediate host of $T$. solium, the pork tapeworm. It can occur in any site of body but oral lesions are rare. As oral cysticercosis is a rare entity; it is a diagnostic challenge to the oral healthcare professionals and is also poorly documented in the scientific literature. Here, we report a case of oral cysticercosis affecting tongue that emphasizes the importance of subjecting even apparently innocuous appearing lesions for histopathological evaluation and routine microscopic examination in diagnosing such lesions.

Copy Right, IJAR, 2018,. All rights reserved.

\section{Introduction:-}

Cysticercus (Kystis - cyst and Kertos - tail). Cysticercosis commonly involves intermuscular and subcutaneous tissues, whereas commonly affected organs are central nervous system and eye. Inspite of abundant intermuscular tissue in oral tissues, it is not a common site for cysticercosis due to high muscular activity and metabolic rate of oral tissues in humans, which act against lodgement and development of cysticerci. The frequently involved oral locations for cysticercosis are tongue, labial or buccal mucosa and mouth floor.The larval stage of T. solium; Cysticercus resides in muscle and other tissues in pigs that serve as intermediate host. Ingestion of inadequately cooked pork containing cysticerci leads to infection in human beings, the definitive host. Human beings can also serve as intermediate hosts through accidental ingestion of $T$. solium eggs. Acquisition of cysticercosis can be by the faecal-oral route and not necessarily by eating pork. This is a more serious condition because the ingested eggs 
develop into embryos (oncospheres) that can penetrate the intestinal wall and disseminate through vascular or lymphatic circulation to develop into cystic larvae (cysticercus cellulosae). Cytomorphology and histopathological findings are confirmatory and necessary before starting treatment.

\section{Case report:-}

A 20 year old male presented with swelling on the right side of the tongue. The patient gave history of swelling which was present for about three years. The swelling was insidious in onset and progressed in size over time. Past medical, dental and family history was non contributory. Patient was not under any medication and there was no history of drug allergy. There was no history of trauma to the area of swelling and no history of any discharge from the swelling. On intraoral examination, a well circumscribed, smooth sub mucosal, nodular swelling of approximately $1.5 \mathrm{~cm}$ in diameter was observed on the right lateral border of the tongue. On palpation, swelling was soft to firm in consistency, non compressible, tender and mobile. The patient had pain and difficulty in eating. The swelling had an intact overlying mucosa and there was no local rise of temperature. There were no palpable lymph nodes present in the head and neck region. Based on these findings, a clinical diagnosis of benign mesenchymaltumour was made and the differential diagnosis considered were mucocele, lipoma, fibroma, hemangioma, lymphangioma, granular cell tumour, minor salivary gland tumour and parasitic cyst. Fine needle aspiration from the swelling was done and it yielded clear fluid and amorphous acellular fragments on cytologic examination. An excisional biopsy was then performed under local anaesthesia and sent for histopathological examination. Gross specimen consisted of multiple greyish white soft tissue pieces measuring approximately $2 \times 1 \mathrm{~cm}$ in size in aggregate. Cut surface was partially solid and partially cystic. Multiple pieces were processed and hematoxylin and eosin staining was done. Microscopically, sections showed a cysticercus cyst with a thick cuticle, subcuticular cells and suckers. Surrounding tissue was infiltrated with eosinophils and plasma cells. Other section showed lobules of minor salivary glands with seromucinousacini along with congested blood vessels. (Fig. 1 \& 2) Based on the histopathological findings, diagnosis of oral cysticercosis was given.

\section{Discussion:-}

In the present case, various benign swellings were considered as differential diagnosis but Cysticercosis was not thought of clinically. Cysticercosis of tongue is a rare entity, and till now only 34 cases have been reported in the scientific literature. Fine needle aspiration of viable cyst of cysticercosis yields clear fluid and fragments of bladder wall in a clear acellular background, whereas aspirates of necrotic lesions contain fragments of bladder wall including calcareous corpuscles and detached single hooklets. Diagnosis of cysticercosis is made on fine needle aspiration cytology only when fragments of larval cuticle and parenchyma are identified, which were absent in present case. Even to suspect about a parasitic infection characteristic inflammatory background comprising of eosinophils, neutrophils, palisading histiocytes and giant cells must be present in the aspirate from a subcutaneous nodule. Again this finding was lacking in the present case. Although, gross and microscopy of cysticercosis are related to evolution of parasite and tissue reaction around it, both are almost similar irrespective of tissue or organ from where they are removed. They consist of well-preserved or dead disintegrating parasites. Usually the growth of cysticercus is slow; eliciting mild inflammatory reaction and only some tissues elicit formation of host capsule around it. After attaining full growth, parasite remains viable for several months to years depending on the location, type of host and other unknown factors. When cysticercus dies in tissues, parasitic antigens leak into surrounding tissues and elicit more inflammatory reaction. Dead or degenerating cyst is slowly invaded by inflammatory cells, macrophages and finally replaced by fibrous tissue with complete resorption of parasite and often dead parasite undergoes calcification. This is frequent when cysticerci are not surrounded by thick fibrous capsule like central nervous system and eye. Histopathological diagnosis is based on the recognition of cysticercus in the excised lesion. Viable cysticercus is usually present in excised tissue from the oral mucosa, breast, conjunctiva, subcutaneous tissues and other sites where presence of cysticercus arouses some concern and is readily accessible. In all cases, typical histologic characteristics of cestode tissue must be recognized, even if morphologically a cysticercus with scolex is not evident. Viable cysticerci of T.solium have typical histological characteristic of bladder wall, scolex and the neck. Calcareous corpuscles which are one of the most important histologic markers of cestode tissue (larve or adult) were not seen, which could be due to exposure of tissue to acid. Presence of neutrophils, lymphocytes and foreign body giant cells in the surrounding tissue were suggestive of ongoing degenerative process, because viable cysticerci do not elicit any inflammatory reaction. However, cysticercus of $T$. soliumis the most common but not the only cysticercus occurring in humans.Cysticercus of other species like T.crassicepss, cysticercusbovis of T.saginatahave also been reported in human. Whenever clear fluid is aspirated and smear shows hooklets, depending on the location, cysticercosis must be considered, especially in case of subcutaneous swellings and intramuscular swellings. However, possibility of hydatid cyst should also be ruled out in such cases. 


\section{Conclusion:-}

In endemic areas, oral cysticercosis should be considered in the differential diagnosis of intraoral solitary swellings of the oral cavity. The case reported here shows the importance of subjecting all the excised oral tissue specimens for histopathological evaluation, since neither the clinical examination nor a history suggested a diagnosis other than a common benign lesion to the clinician. Therefore, clinicians and oral pathologists should be aware of such uncommon lesion and should consider it in the differential diagnosis.

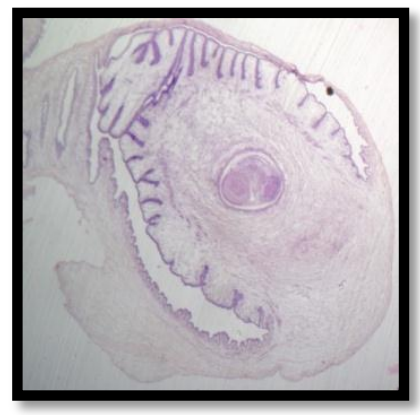

Figure 1:-Photomicrograph showing cysticercus cellulosae with a cuticle, subcuticular cells and sucker (40x)

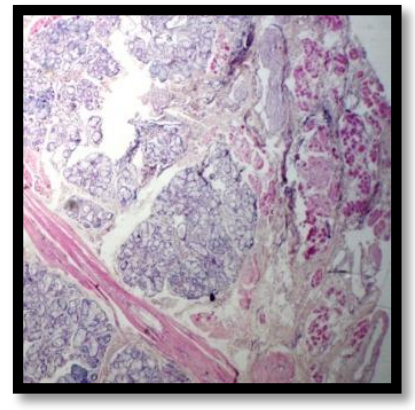

Figure 2:-Photomicrography showing seromucinous acini of minor salivary gland of tongue (40x)

\section{References:-}

1. Elias FM, Martins MT, Foronda R, Jorge WA, Araújo NS. Oral cysticercosis: case report and review of the literature. Rev Inst Med Trop Sao Paulo. 2005;47(2):95-8.

2. Meher R, Gupta B, Aggarwal S, Passey JC. Cysticercosis of tongue - A case report. Indian J Otolaryngol Head Neck Surg. 2006;58(2):185-87.

3. Prasad KN, Prasad A, Verma A, Singh AK. Human cysticercosis and Indian scenario: a review. J Biosci. 2008;33(4):571-82.

4. Koteeswaran G, Mangala G, Kotasthane DS, Tirou AT. Cysticercosis of tongue: Cytohistologic approach to diagnosis. J Oral MaxillofacPathol 2013;17:480.

5. Hosur MB, Byakodi S, Puranik RS, Vanaki SS, Surekha R. Puranik SR, Shivakumar MS. Oral Cysticercosis: A Case Report and Review of Literature. J. Maxillofac. Oral Surg. 2015;14(3):853-857 